\title{
Nest composition, stable isotope ratios and microbiota unravel the feeding behaviour of an inquiline termite
}

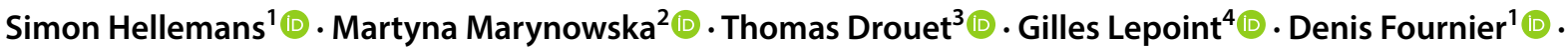 \\ Magdalena Calusinska ${ }^{2} \cdot$ Yves Roisin $^{1}$ (D)
}

Received: 25 February 2019 / Accepted: 21 September 2019 / Published online: 30 September 2019

(c) Springer-Verlag GmbH Germany, part of Springer Nature 2019

\begin{abstract}
Termites are eusocial insects having evolved several feeding, nesting and reproductive strategies. Among them, inquiline termites live in a nest built by other termite species: some of them do not forage outside the nest, but feed on food stored by the host or on the nest material itself. In this study, we characterized some dimensions of the ecological niche of Cavitermes tuberosus (Termitidae: Termitinae), a broad-spectrum inquiline termite with a large neotropical distribution, to explain its ecological success. We used an integrative framework combining ecological measures (physico-chemical parameters, stable isotopic ratios of $\mathrm{N}$ and $\mathrm{C}$ ) and Illumina MiSeq sequencing of 16S rRNA gene to identify bacterial communities and to analyse termites as well as the material from nests constructed by different termite hosts (the builders). Our results show that (1) nests inhabited by $C$. tuberosus display a different physico-chemical composition when compared to nests inhabited by its builder alone; (2) stable isotopic ratios suggest that $C$. tuberosus feeds on already processed, more humified, nest organic matter; and (3) the gut microbiomes cluster by termite species, with the one of $C$. tuberosus being much more diverse and highly similar to the one of its main host, Labiotermes labralis. These results support the hypothesis that $C$. tuberosus is a generalist nest feeder adapted to colonize nests built by various builders, and explain its ecological success.
\end{abstract}

Keywords Isoptera $\cdot$ Termitidae $\cdot$ Cavitermes tuberosus $\cdot$ Humivorous $\cdot$ Neotropical $\cdot$ Nitrogen $\cdot$ Nest

Communicated by Liliane Ruess.

Electronic supplementary material The online version of this article (https://doi.org/10.1007/s00442-019-04514-w) contains supplementary material, which is available to authorized users.

Simon Hellemans

simon.hellemans@gmail.com

1 Evolutionary Biology and Ecology, Université Libre de Bruxelles, Avenue F.D. Roosevelt 50, CP 160/12, 1050 Brussels, Belgium

2 Environmental Research and Innovation Department, Luxembourg Institute of Science and Technology, 4422 Belvaux, Luxembourg

3 Laboratoire d'Écologie Végétale et Biogéochimie, Université Libre de Bruxelles, Avenue F.D. Roosevelt 50, CP 244, 1050 Brussels, Belgium

4 Laboratory of Oceanology-MARE, University of Liège, FOCUS UR, 11 allée du six août, 4000 Liège, Belgium

\section{Introduction}

Termites are eusocial insects having evolved several feeding and nesting strategies. They feed on microepiphytes, grass, dead or living wood, and humus (Eggleton and Tayasu 2001). Based on the gut content and the anatomy of workers, termites can be classified into four feeding groups reflecting the degree of decomposition of organic matter on which they feed (Donovan et al. 2001): group I and II are composed of wood, litter and grass feeders; termites of group III feed on very decayed wood or soil with high organic content; and group IV comprises feeders of soil with low organic content. While group I only contains lower termites, the other three groups consist of higher termites (Termitidae).

Another classification, based on lifetypes, describes the degree of association between nest site and food source (Abe 1987): single-piece nesters, which feed and nest in the same substrate; intermediate nesters, feeding both on their nest and outside; and separate-piece nesters, which actively forage outside. While the first two categories consist of only wood-feeding termites, termites of the third category display 
a broader range of possible diet. A fourth lifetype can also be recognized and consists of inquiline termites, living in nests built by another species (Shellman-Reeve 1997): their association ranges from facultative to obligatory inquilinism. Among obligatory inquilines, the best known examples are Serritermes serrifer (Serritermitidae) nesting only in nests of Cornitermes species (Termitidae: Syntermitinae) (Araujo 1977), and the genus Inquilinitermes (Termitidae: Termitinae) always nesting in the lower part of nests of Constrictotermes species (Termitidae: Nasutitermitinae) (Noirot 1970). The benefits of using a nest built by another species are numerous: inquilines avoid the cost of building and maintaining the nest, and profit from a shelter against environmental conditions and predators (Shellman-Reeve 1997). One major peculiarity in the lifestyle of some inquiline termites is that they do not forage outside the nest, but feed on food stored by the host or on the nest material itself, which may be considered a special form of humivory (Myles 1999; Bourguignon et al. 2011; Florencio et al. 2013). Most of the obligatory inquiline termites belong to the subfamily Termitinae from the Termitidae (Shellman-Reeve 1997).

The family Termitidae is the most phylogenetically recent (ca. 54 Mya; Bourguignon et al. 2015b, 2017) and species rich of all families (70\% of described termites; Krishna et al. 2013a). It is characterized by the loss of cellulolytic flagellates and by displaying an entirely prokaryotic gut microbiota that brought along dietary diversification and tremendous ecological success (Bignell and Eggleton 2000; Eggleton and Tayasu 2001; Ohkuma and Brune 2011; Brune and Dietrich 2015). While it has long been thought that diet, gut microenvironment and vertical transmission were the primary determinants of bacterial communities (Abdul Rahman et al. 2015; Mikaelyan et al. 2015, 2017; Su et al. 2017), a recent study evidenced rampant horizontal transfer over evolutionary time between termite species with both vertical (colony-to-offspring) and horizontal (colony-to-colony) transmission (Bourguignon et al. 2018). Such mechanisms may be particularly important in inquiline-host pairs, but are yet to be investigated (Mikaelyan et al. 2015, 2017).

Cavitermes tuberosus (Emerson 1925) is a broad-spectrum inquiline colonizing arboreal nests built by other species, with a large neotropical distribution (Mathews 1977; Constantino 1991; Martius 1997; Apolinário and Martius 2004; Krishna et al. 2013b). This species was demonstrated to undergo asexual queen succession: queens sexually produce several generations of winged reproductives that disperse and colonize new nests, while they parthenogenetically produce numerous secondary queens that reproduce within their mother's nest, thereby increasing the colony reproductive output (Fournier et al. 2016; Hellemans et al. 2017b, 2019a). Also, these secondary reproductives are small, which may present the advantage of remaining able to circulate through the small galleries at the margins of the host's nest-a probable constraint for physogastric queens. These features appear particularly advantageous for species with an inquiline lifestyle. According to the classification of Donovan et al. (2001), C. tuberosus belongs to soil feeders of group III (Davies 2002; Davies et al. 2003). As it has never been observed to forage outside, this suggests that its main or exclusive food source may be the nest material of other termite species. To test this hypothesis, we used an integrative framework combining classical ecological measures with next-generation sequencing. More specifically, we (1) investigated for signs of nest consumption by analysing 26 physico-chemical parameters of nests corresponding to several stages of colonization by C. tuberosus; (2) measured the ratios of stable isotopes of nitrogen and carbon in nests and termite tissues to determine whether $C$. tuberosus feeds on nest material, i.e., on already processed, more humified organic matter (Hood-Nowotny and Knols 2007; Hyodo et al. 2008; Potapov et al. 2019); (3) determined the composition of bacterial communities present in the nests and guts of $C$. tuberosus using Illumina high-throughput sequencing of the bacterial 16S rRNA gene, to see if $C$. tuberosus shares gut microbiota with its hosts, irrespective of termite phylogeny (Mikaelyan et al. 2015; Bourguignon et al. 2018); and (4) identified OTUs potentially involved in the process of nitrogen fixation, a process that would balance the loss of nitrogen through the remineralisation of the nest material, which may be of importance in arboreal systems.

\section{Materials and methods}

\section{Study site and model organism}

The study was conducted in the tropical rainforest surrounding the Petit Saut dam area (N $05.07^{\circ}$, W $\left.52.87^{\circ}\right)$ in French Guiana. The mean annual temperature is $26^{\circ} \mathrm{C}$, and this area experiences approximately $3000 \mathrm{~mm}$ of rainfall with peaks in December-January and April-June. The region is covered by mature lowland forest with canopy height reaching 30-40 m on a well-drained lateritic tropical soil (de Granville 1988; Cosson et al. 1999).

According to our extensive sampling in French Guiana between 2012 and 2017, C. tuberosus lives in arboreal structures: (1) in an indistinct layer of soil material covering the roots or on the basis of tree trunks, in cavities within tree trunks, between the stems of palm trees (Astrocaryum spp., Arecaceae), (2) in mounds against trees or well-defined arboreal nests built by other termite species; in this case, the nest may be abandoned or still inhabited by the initial builder, and sometimes by other colonizing species. If $C$. tuberosus shares a nest with another species, they live in separate galleries. Cavitermes tuberosus was mostly found in arboreal nests of Labiotermes labralis and Silvestritermes 
heyeri, rarely in nests of Silvestritermes minutus (all belonging to the Termitidae: Syntermitinae), in the uppermost part of mounds build by the Termes fatalis species complex (sensu Hellemans et al. 2017a) and in nests of Neocapritermes taracua (Termitidae: Termitinae) at the base of trees. Co-occurring species with $C$. tuberosus in abandoned nests were Nasutitermes spp. and Subulitermes-group species (Termitidae: Nasutitermitinae), and Anoplotermes-group species (Termitidae: Apicotermitinae).

\section{Ecological measurements}

\section{Physico-chemical analyses of termite nests}

In 2017, we collected 39 termite nest fragments in the Petit Saut dam area, French Guiana (Table S1). Approximately $50 \mathrm{~g}$ of nest soil material was obtained by gently crushing a portion of nest with a pestle and mortar to obtain fine aggregates. Soil samples were dried in an oven at $60^{\circ} \mathrm{C}$ until measurements were made. Nest fragments were divided into two categories reflecting the colonization stage by $C$. tuberosus: category A included nests inhabited by their builder only (L. labralis, N. taracua, S. heyeri, or T. fatalis; $n=12$ ) and category B included nests in which $C$. tuberosus coexisted with the nest builder $(n=5)$, or nests with $C$. tuberosus only $(n=22)$.

We used 26 physico-chemical parameters to characterize nest material samples. First, we measured four classical parameters according to standard protocols (Pansu and Gautheyrou 2006): $\mathrm{pH}_{\mathrm{H} 2 \mathrm{O}}$, electrical conductivity (EC, in $\left.\mathrm{mS} \mathrm{cm}{ }^{-1}\right)$, organic matter content $(\mathrm{OM})$ and the relative proportion of humic and fulvic acids in the OM. Nest $\mathrm{pH}$ and EC were measured on a 1:5 sample:deionized water (v/v) blend after $2 \mathrm{~h}$ agitation, respectively, with glass electrodes (Mettler-Toledo) and a conductimeter (VWR EC300). OM in the nest was estimated by sample mass loss after dry ashing for $12 \mathrm{~h}$ at $500{ }^{\circ} \mathrm{C}$. Fulvic acids are comparatively more abundant than humic acids in topsoils while they equilibrate in the nests, as well as in faeces, after gut passage (GarnierSillam and Harry 1995; Brauman 2000; Ji et al. 2000). The humification stage was quantified using the extinction coefficient in visible light (E4/E6) which reflects the relative proportion of humic and fulvic acids in the OM. Humic acids are characterized by ratios below 5.0, while ratios of fulvic acids are between 6.0 and 8.5, so the lower the ratio, the higher the proportion of humic relative to fulvic acids in the solution (Schnitzer 1971). This coefficient was obtained by measuring the absorbance on a UV-VIS Hitachi U-2900 spectrophotometer (Tokyo, Japan) at 465 and $665 \mathrm{~nm}$ of a suspended solution of nest soil incubated under agitation with $0.05 \mathrm{M} \mathrm{NaHCO}_{3}$ at $\mathrm{pH} 8.5$ for $24 \mathrm{~h}$ and centrifuged for $5 \mathrm{~min}$ at $5000 \mathrm{rpm}$.
Second, we quantified the concentration of 18 bioavailable-essential (B, Ca, Co, Cr, Cu, Fe, K, Mg, Mn, Mo, $\mathrm{Ni}, \mathrm{P}, \mathrm{S}, \mathrm{Zn})$, non-essential $(\mathrm{Al}, \mathrm{Ba})$ and toxic $(\mathrm{Cd}, \mathrm{Pb})-$ elements in the nest (dry weights, expressed in $\mu \mathrm{g} \mathrm{g}^{-1}$ ) after extraction with $0.5 \mathrm{M} \mathrm{NH}_{4}$-acetate $0.03 \mathrm{M}$ EDTA at $\mathrm{pH} 4.65$ during $1 \mathrm{~h}$ and subsequently quantified by inductively coupled plasma optical emission spectroscopy (ICPOES) with CCD detector (Varian, Vista MPX). Finally, we determined the total $\mathrm{C}$ and $\mathrm{N}$ contents (\%) and isotopic ratios (hereafter $\delta^{13} \mathrm{C}$ and $\delta^{15} \mathrm{~N}$, respectively) from nest samples (see below). Raw data of the 26 physico-chemical parameters of nests are given in Supplementary File 1.

\section{Isotopic analyses}

Termite tissues from all species ( $n=42$ colonies, from five species), nests ( $n=39$; Table $\mathrm{S} 1)$ and samples from the topsoil layer $(n=4)$ were subjected to $\mathrm{C}$ and $\mathrm{N}$ isotopic analyses. To avoid contamination from gut content, we dissected heads of 25 workers and directly stored them in $96 \%$ ethanol at $-20{ }^{\circ} \mathrm{C}$ until use. Storage in $96 \%$ ethanol preserves tissues for morphological and genetic analyses and isotopic ratios are not altered (Florencio et al. 2011). Tissue samples were dried at $60{ }^{\circ} \mathrm{C}$ for $24 \mathrm{~h}$ in a stove prior to weighing. Because carbonate isotopic composition is generally different from organic carbon isotopic composition, carbonates must consequently be removed from samples if present: their absence from dried samples of nests and topsoil was ascertained by reaction with $\mathrm{HCl} 10 \%$, and no acidification was therefore performed. Replicates of $0.50-1.00 \mathrm{mg}$ and 5-10 $\mathrm{mg}$ of dried termite tissues and nest samples, respectively, were weighted in tin capsules using a Mettler AT261 DeltaRange (MettlerToledo) precision balance $(0.01 \mathrm{mg})$.

All samples were analysed for $\delta^{13} \mathrm{C}$ and $\delta^{15} \mathrm{~N}(\% \circ)$ via continuous flow elemental analysis-isotope ratio mass spectrometry (CF-EA-IRMS) at the University of Liège (Belgium) using a vario MICRO cube elemental analyzer (Elementar Analysensysteme GmbH, Hanau, Germany) coupled to an IsoPrime 100 mass spectrometer (Isoprime, Cheadle, United Kingdom). Sucrose (IAEA-C6; mean $\left.\pm \mathrm{SD}: \delta^{13} \mathrm{C}=-10.8 \pm 0.5 \% 0\right)$ and ammonium sulphate (IAEA- $\mathrm{N}_{2} ; \delta^{15} \mathrm{~N}=20.3 \pm 0.2 \%$ ) were used as certified reference materials (CRM). Both CRMs are calibrated against international isotopic references, i.e., the Vienna Pee Dee Belemnite (VPBD) for carbon and atmospheric air for nitrogen. The standard deviations of the multi-batch replicate measurements of lab standards (amphipods) as well as glycine (Merck, Darmstadt, Germany) interspersed among the samples were $0.1 \%$ and $0.2 \%$ for $\delta^{13} \mathrm{C}$ and $\delta^{15} \mathrm{~N}$, respectively. Raw data are given in Supplementary File 1. 


\section{Statistical analyses}

All following analyses were performed using R v3.1.3 (R Development Core 2015). To investigate for changes in the 26 measured physico-chemical parameters of nests colonized by $C$. tuberosus, we first performed a principal component analysis (PCA; for details, see Supplementary Figure $\mathrm{S} 1)$ to describe the overall changes between nest categories and plotted the first two principal components (PC) using the ggord package (Beck 2017). Additionally, we performed a linear discriminant analysis (LDA; "lda" function from the MASS package). Prior to LDA, we performed log transformation and standardization of variables, excluding collinear variables (at threshold 0.70; "vifcor" function from the usdm package) and verifying multivariate homogeneity of withingroup covariance matrices ("betadisper" function from the vegan package). Significance of pre-defined categories was determined using a Welch two-sample $t$ test on the scores of the first linear discriminant (LD1). Finally, we performed Wilcoxon rank-sum tests on each original variable and corrected $p$ values for multiple comparisons using the false discovery rate (FDR) method (Benjamini and Hochberg 1995).

Isotopic niches of each species were inferred from the biplot of $\delta^{13} \mathrm{C}$ and $\delta^{15} \mathrm{~N}$ and were computed as Bayesian standard ellipses using SIBER (SIAR package) (Parnell et al. 2010; Jackson et al. 2011). Diet spaces were compared using MANOVA on both $\delta^{13} \mathrm{C}$ and $\delta^{15} \mathrm{~N}$ followed by univariate analyses using Kruskal-Wallis rank-sum tests and pairwise species comparisons with post hoc Nemenyi's tests (from PMCMR package).

\section{Diversity and composition of bacterial communities from termite guts and nests}

Wild mature workers of $C$. tuberosus and several of its hosts (L. labralis, N. taracua, S. heyeri, S. minutus and T. fatalis) were collected from 23 nests in March 2016 and January 2017 (for details see Table S1). Individuals were cold immobilized and surface cleaned with $80 \%$ ethanol and $1 \mathrm{X}$ PBS. Whole guts (WG) from 26 samples (Table S1; each in triplicate; $n \approx 30 \mathrm{WG}$ per replicate) were dissected with sterile forceps, pooled and directly preserved on site in liquid nitrogen (in few cases more than one species inhabited a single nest). Additionally, triplicates of approximately $250 \mathrm{mg}$ were preserved from 19 nest samples (Table S1). Nucleic acids from both whole guts and nest samples were extracted using Power Viral Environmental RNA/DNA Isolation Kit (MO-BIO) with $0.1 \mathrm{~mm}$ glass beads, following manufacturer's instructions supplemented by a cell lysis step by beadbeating at $20 \mathrm{~Hz}$ for $2 \mathrm{~min}$. In the case of nest samples, the extraction was preceded by crushing the piece of mound with sterile mortar and by shaking the resulting powder in a tube with glass beads and $750 \mu \mathrm{L}$ of buffer PV1 for $45 \mathrm{~min}$ at $500 \mathrm{rpm}$ at $22{ }^{\circ} \mathrm{C}$. The obtained DNA was treated with $1 \mu \mathrm{L}$ of $10 \mu \mathrm{g} / \mathrm{mL}$ RNase A (Sigma) at room temperature (RT) for 30 min and quantified by Qubit dsDNA HS Assay Kit. The bacterial 16S rRNA gene libraries were prepared using an Illumina platform-compatible approach as previously applied by Marynowska et al. (2017) in the study of the termite gut bacterial communities.

After demultiplexing and quality trimming, resulting sequencing reads were assigned to operational taxonomic units (OTUs) at $97 \%$ similarity with Usearch pipeline v7.0.1090_win64 (Edgar 2010), and further taxonomically annotated with SILVA database $v 128$ (Pruesse et al. 2007) using mothur software v1.38.0 (Schloss et al. 2009). Due to high reproducibility of triplicates (Fig. S2; Table S3), reads resulting from replicates were pooled and analysed together. Additionally, to ensure even coverage across samples, sequences were subsampled to 10,000 reads per sample. The average pairwise Bray-Curtis distance for each gut bacterial community of Cavitermes and their hosts were calculated using mothur ("dist.shared" function), visualized using principal coordinate analysis (PCoA; "pcoa" function in mothur), and compared statistically using Wilcoxon signed-rank test (different if $p<0.001$ ). Statistical analyses were performed using mothur and R environment (R Development Core 2015) on the OTUs annotated as of prokaryotic origin. The quality-checked dataset is available in the GenBank repository under project accession KBWO01000000 (see details in Supplementary Table S2).

In addition, we investigated for the presence of bacteria potentially involved in nitrogen fixation, which may be of importance in arboreal systems. To do so, we blasted our 16S rRNA sequences against the complete prokaryotic RefSeq genomes database from NCBI. Using the threshold of $97.0 \%$ identity, OTUs potentially involved in the process of nitrogen fixation in gut as well as nests samples were identified, based on the presence of genes encoding for nitrogenase (nif subunits) in the matched genomes.

\section{Results}

\section{Ecological measurements on nests colonized by $C$. tuberosus}

PCA revealed a strong overlap between the two nest categories (for details, see Supplementary Fig. S1). Prior to LDA, 5 of the $26 \log$-transformed and standardized parameters of nests were excluded due to collinearity $(\mathrm{Fe}, \mathrm{Cd}, \mathrm{Cr}, \mathrm{Co}$ and $\mathrm{C})$ : the first 4 strongly covaried among them and with $\mathrm{Pb}$, as well as $\mathrm{Fe}$ and $\mathrm{Co}$ with $\mathrm{Al}, \mathrm{Cr}$ with $\mathrm{Cu}$ and $\mathrm{Ni}$, while $\mathrm{C}$ covaried with $\mathrm{OM}$ and $\mathrm{N}$. The first linear discriminant (LD1) correlated the most with $\mathrm{Al}$ and $\mathrm{Cu}(13.42 \%$ and $11.90 \%$, respectively), and nest categories significantly differed 
on LD1 (Welch two-sample $t$ test: $t=-10.88, d f=17.76$, $p<0.001)$.

Wilcoxon rank-sum tests on the 26 physico-chemical parameters of nests showed that OM $(p=0.049)$ and $\delta^{13} \mathrm{C}$ values $(p=0.012)$ decreased in nests colonized by $C$. tuberosus (category B) compared with those inhabited by the builder only (category A; Table S6), while the concentration of $\mathrm{Al}, \mathrm{Cd}, \mathrm{Co}, \mathrm{Cr}, \mathrm{Cu}, \mathrm{Fe}, \mathrm{Mg}, \mathrm{Ni}$ and $\mathrm{Pb}$ (all $p<0.05$ ) was higher in $\mathrm{B}$ nests. When corrected for multiple comparisons with the FDR method, only the effects of $\delta^{13} \mathrm{C}, \mathrm{Al}, \mathrm{Cd}$, $\mathrm{Co}, \mathrm{Cr}, \mathrm{Cu}$ and $\mathrm{Fe}$ remained significant (all $p<0.05$ ). Also, humification stage of nests could not be differentiated and similar proportions of humic and fulvic acids were found in A and B nests (Table S6; Welch two-sample $t$ test: $t=-0.75$, $\mathrm{df}=15.81, p=0.46)$, and the $\mathrm{C}: \mathrm{N}$ ratio of nests was similar between A and B nests (Wilcoxon rank-sum tests; $W=211$, $p=0.299$ ).

\section{Isotopic analyses on nest material and termite tissues}

Isotopic $\delta^{13} \mathrm{C}$ values ranged from -26.4 to $-30.1 \%$ and $\delta^{15} \mathrm{~N}$ values from 1.8 to $6 \%$ for nest samples $(n=37)$, and were similar to those from topsoil samples $(n=4$; Fig. 1a). The $\mathrm{C}: \mathrm{N}$ ratio of nests was positively correlated to $\delta^{13} \mathrm{C}$ (linear regressions; $\left.R^{2}=0.30, F_{1,35}=15.09, p<0.001\right)$, and negatively to $\delta^{15} \mathrm{~N}\left(R^{2}=0.22, F_{1,37}=10.35, p=0.003\right)$. Nests inhabited by $C$. tuberosus exhibited a significant enrichment in ${ }^{13} \mathrm{C}$ compared to A nests (Table S6; Wilcoxon ranksum tests; $W=68, p=0.012$ ), while $\delta^{15} \mathrm{~N}$ values marginally increased $(W=100, p=0.06)$.

In termite tissues, isotopic ratios ranged from -22.7 to $-28.3 \%$ for $\delta^{13} \mathrm{C}$ and from 5.9 to $14.1 \%$ for $\delta^{15} \mathrm{~N}(n=138)$. Overall, species differed in their stable isotopic ratios on both dimensions (Fig. 1b; MANOVA; Wilks' $\lambda=0.14$, $F_{4,133}=54.48, p<0.001$ ), and follow-up univariate analyses indicated that species differed in both $\delta^{15} \mathrm{~N}$ and $\delta^{13} \mathrm{C}$ values (Kruskal-Wallis tests; $\delta^{15} \mathrm{~N}: H_{4}=63.52, p<0.001$; $\left.\delta^{13} \mathrm{C}: H_{4}=95.57, p<0.001\right)$. Most species differed in $\delta^{15} \mathrm{~N}$ values (post hoc Nemenyi's test; all $p<0.04$ ) except for comparisons of $C$. tuberosus to L. labralis and to $S$. heyeri; $N$. taracua to $S$. heyeri and to T. fatalis. For $\delta^{13} \mathrm{C}$ values, differences were observed between $C$. tuberosus and all species, and between L. labralis and T. fatalis (post hoc Nemenyi's test; all $p<0.02$ ). Also, isotopic niches of species never overlapped in nests in which both the builder and $C$. tuberosus cohabited (Fig. S3).

Cavitermes tuberosus exhibited the broadest range of values for both isotope ratios $\left(\delta^{13} \mathrm{C}\right.$ range: $3.5 \%$; $\delta^{15} \mathrm{~N}$ range: $6.8 \%$; Table S7), and values were positively correlated with those of their nests (linear regressions; $\delta^{13} \mathrm{C}: R^{2}=0.77$, $F_{1,75}=252.6, p<0.001 ; \delta^{15} \mathrm{~N}: R^{2}=0.38, F_{1,78}=48.16$, $p<0.001)$. Finally, the isotopic niche of $C$. tuberosus did not differ when considering the nest builder identity (Fig. S4).

\section{Diversity and composition of bacterial communities from termite guts and nests}

The diversity and composition of the gut and the nest microbiota of $C$. tuberosus and its hosts were assessed by highthroughput 16S rRNA gene amplicon sequencing. Quality-trimmed reads from 45 samples were normalized and assigned to 7514 prokaryotic OTUs using the $97 \%$ sequence similarity threshold (see Supplementary File 2). Number of OTUs per sample varied from 792 to 1733 OTUs for the gut samples, and from 187 to 990 OTUs for the nest samples. Gut samples showed a higher richness and diversity than nest samples (Wilcoxon signed-rank tests; richness: $W=0, p<0.001$; inverse Simpson diversity index: $W=10$, $p<0.001$ ), and only a few OTUs were shared between corresponding pairs of samples (Table S4). Rarefaction curve analysis indicated that the dominant bacterial diversity was captured for most of the tested samples (Fig. S5). An increased sequencing depth would have allowed describing on average $212 \pm 49$ bacterial OTUs in the case of the gut samples and $183 \pm 90$ in the case of the nest samples, as indicated by Boneh's estimator implemented in mothur.

Bacterial communities of the $C$. tuberosus guts were characterized by the highest average richness (Table S4; Welch two-sample $t$ test; $t=5.465, \mathrm{df}=16.003, p<0.001$ ) and diversity (inverse Simpson diversity index; Wilcoxon rank-sum test, $W=164, p<0.001)$ compared to nest builders. In the case of the nest extracts, the diversity and richness were similar between nests inhabited by $C$. tuberosus or by its builder (Wilcoxon rank-sum tests; richness: $W=33, p=0.395$; inverse Simpson diversity index: $W=38$, $p=0.657)$. In total, 28 prokaryotic phyla were detected in the gut samples, out of which 13 were represented by at least 100 reads (1\% relative abundance) in at least 1 sample. In the case of the nest samples, 30 phyla were identified (12 with at least $1 \%$ relative abundance).

Within the gut microbiome, Spirochaetae and Firmicutes were the most dominant phyla (Fig. 2a). At the family level, the majority of OTUs were classified to Ruminococcaceae and Spirochaetaceae. In general, similar taxa were present across all gut samples, but their relative abundances varied between termite species. Furthermore, bacterial communities clustered by termite species on the Bray-Curtis-based principal coordinate analysis (PCoA) graph at the OTU level (Fig. 2b), and revealed a dissimilarity higher between hosts (min-max: 0.86-0.97) than between Cavitermes and its hosts (0.79-0.93; Wilcoxon signed-rank test; $W=88$, $p<0.001)$. On average, Cavitermes shared over $14.8 \% \pm 2.3$ of gut OTUs with its hosts (see Table S5a for details), and the number of shared OTUs was higher between Cavitermes 
Fig. 1 Stable isotope ratios of carbon $\left(\delta^{13} \mathrm{C}\right)$ and nitrogen $\left(\delta^{15} \mathrm{~N}\right)$ of a the topsoil layer (yellow diamond dots), nests (round dots) and tissues (square dots) from nest builders (black) and C. tuberosus (red), with ellipses computed for the topsoil layer, nests and tissues; and b tissues of nest builders and C. tuberosus, with dot colour and shape representing the termite identity and nest builder, respectively, and ellipses for all species. Ellipses were computed as Bayesian standard ellipses.

This figure is available in colour in the online version
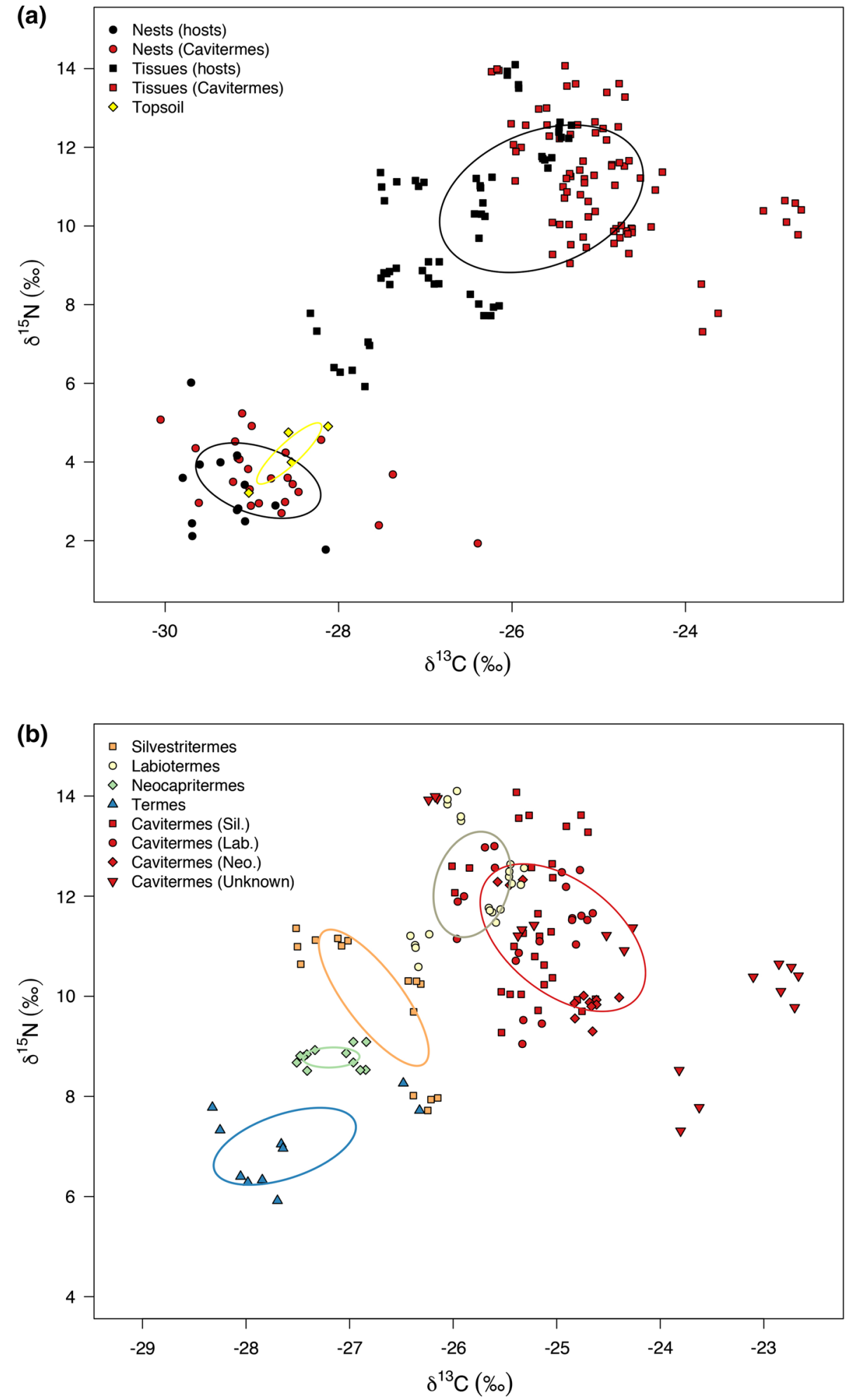

and Labiotermes (its main host) than with the other termite hosts (Fig. 2c).

In the case of the nest microbiomes, the phylum Actinobacteria accounted for an average of $65 \% \pm 15.3$ of the relative community abundance (Fig. 3). The majority of the remaining prokaryotic OTUs was assigned to the phylum Proteobacteria (on average 23\% \$9.6). On average, $3.8 \% \pm 3.3$ of nest OTUs were shared with gut OTUs, 
Fig. 2 Gut community profiles based on the 16S rRNA gene amplicon high-throughput sequencing. a Taxonomic distribution of prokaryotic OTUs into major phyla (annotated according to SILVA database $v 128$ ) for $C$. tuberosus and its hosts: $S$. heyeri, S. minutus, L. labralis, $N$. taracua and T. fatalis. Relative abundances were derived based on a number of normalized reads assigned to specific OTUs. b Principal coordinate analysis (PCoA) based on the Bray-Curtis dissimilarities in prokaryotic community structures at the OTU level. c Boxplots indicating shared OTUs between $C$. tuberosus and its hosts. This figure is available in colour in the online version
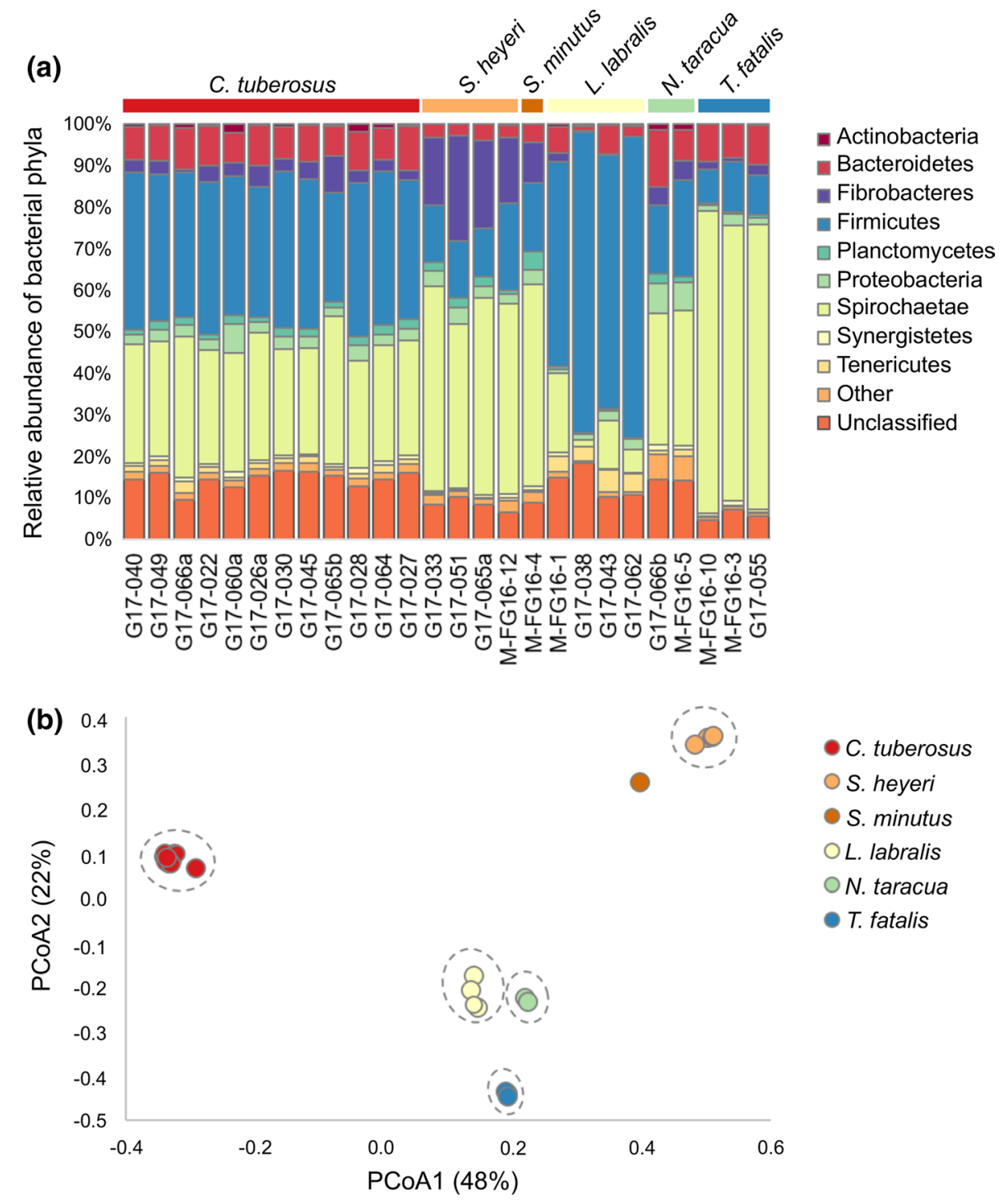

C. tuberosus
S. heyeri
S. minutus
L. labralis
N. taracua
T. fatalis

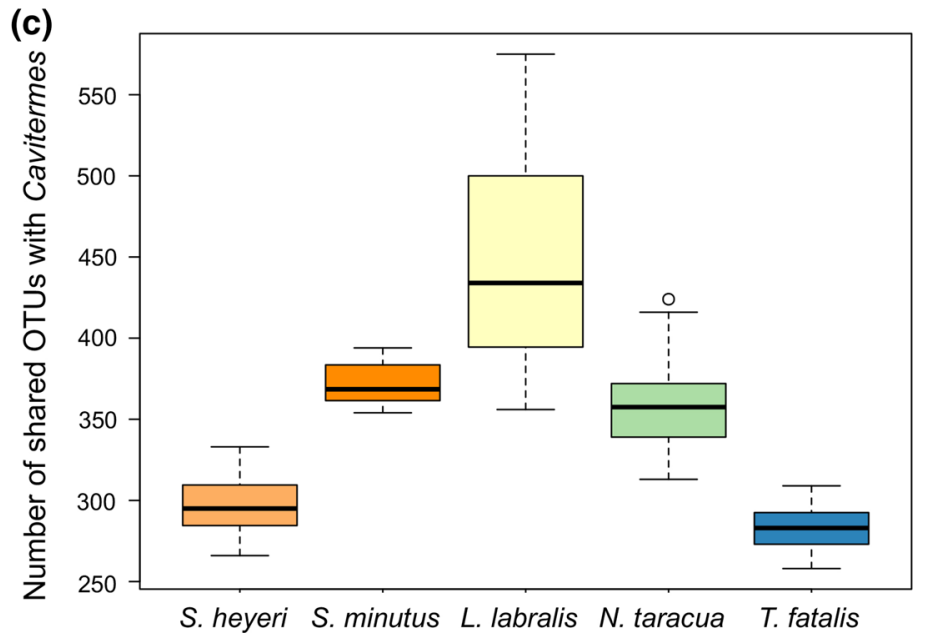

reaching $4.3 \% \pm 2.9$ when comparing OTUs from Cavitermes guts to OTUs from all nests (see Table S5b for details). Number and proportion of shared OTUs between paired samples of nests and guts are given in Table S4. 
Fig. 3 Nest community profiles based on the 16S rRNA gene amplicon high-throughput sequencing. Taxonomic distribution of prokaryotic OTUs into major phyla (annotated according to SILVA database $v 128$ ) for $C$. tuberosus and its major hosts: S. heyeri, L. labralis, $N$. taracua and $T$. fatalis. Relative abundances were derived based on a number of normalized reads assigned to specific OTUs. This figure is available in colour in the online version

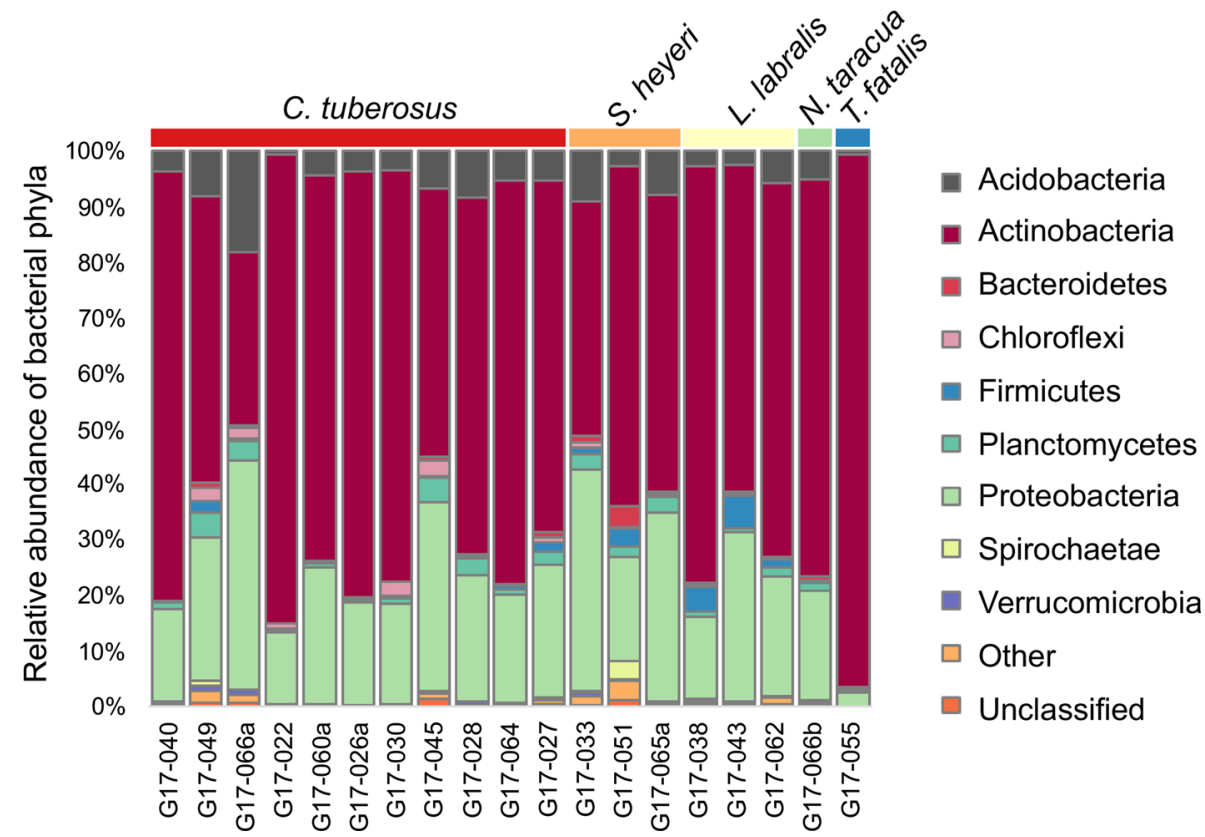

\section{Nitrogen-fixing bacteria in termite guts and nests}

By matching the $16 \mathrm{~S}$ rRNA OTUs from our study to the 16S rRNA genes from the whole prokaryotic RefSeq genomes database, we identified species potentially involved in nitrogen fixation in our samples. As a result, 38 bacterial OTUs were assigned as prokaryotes putatively involved in nitrogen fixation. In general, their relative abundance was higher in the nest microbiomes than in the gut microbiomes $(2.33 \% \pm 3.22$ vs $0.14 \% \pm 0.10$ of all reads; details in Table $\mathrm{S} 4$ ). Nest prokaryotic communities with the presumed nitrogenase activities were mainly dominated by the orders Burkholderiales, Frankiales and Rhizobiales. In the gut microbiomes, lineage I of Elusimicrobia constituted the majority.

\section{Discussion}

In the present work, we characterized some dimensions of the ecological niche of the generalist inquiline $C$. tuberosus. Our results show that (1) nests inhabited by C. tuberosus display a different physico-chemical composition when compared to nests inhabited by its builder alone; (2) $C$. tuberosus exhibits the broadest range of values for both isotope ratios, as well as the highest ones compared to all other species; (3) its gut microbiota is the most diverse, and a significant proportion of OTUs is shared with its hosts; and (4) nest microbiota harbours a small proportion of putative nitrogen fixers.

\section{Nutrient-rich arboreal nests}

Our results show that nests are overall rich in nutrients, and also indicate that the two categories differ in their composition: nests secondarily colonized by $C$. tuberosus are significantly enriched in some elements $(\mathrm{Al}, \mathrm{Cd}, \mathrm{Co}, \mathrm{Cr}, \mathrm{Cu}$ and $\mathrm{Fe})$. Organic matter content $(\mathrm{OM})$ is similar between host-inhabited and secondarily colonized nests (Table S6), and the $\mathrm{C}: \mathrm{N}$ ratio of nests did not differ. A previous study in French Guiana indicated that abandoned termite nests were richer in $\mathrm{OM}$ and elements compared with bare soil, making them attractive for secondary occupancy (Bourguignon et al. 2015a). However, studies on mound-building termites from Brazilian Cerrado showed that nests inhabited by primary termites were richer in elements and OM than secondarily colonized nests, and that some nutrients (e.g., nitrate) leach from the latter (Rückamp et al. 2009, 2012). This observation is in contrast to the higher concentration of elements found in the arboreal nests inhabited by $C$. tuberosus. This can be explained by the fact that $C$. tuberosus often colonizes the nest when it is still occupied by its builder, which keeps on bringing further material to the nest. Alternatively, some nutrients in recalcitrant forms may become bioavailable - and therefore detectable by the methods used hereafter passage through the gut of inquilines (Bottinelli et al. 2015; Jouquet et al. 2016), or the relative proportions of elements might be altered by the leaching of mobile elements or soil components (OM). Furthermore, contrary to mounds, arboreal nests are protected from leaching by rain-shedding structures (Emerson 1956; Wood 1988), so that they may be less prone to elements runoff. 


\section{Isotopic compositions of nests and tissues}

Our data show that isotopic spaces differed between species, sometimes in both dimensions (Fig. 1b), and were consistent with previous measurements from the same study site (Bourguignon et al. 2011). Co-occurring soil-feeding species usually exhibit different isotopic values (Bourguignon et al. 2009, 2011), and this is also the case for species co-habiting within a single mound, i.e., for the builder and the inquiline (Florencio et al. 2013; Fig. S3). Distinct isotopic niches would indicate that species feed on distinct components of the soil and thereby avoid competition.

Termites selectively use soil particles to build different parts of their nests, as shown by different $\mathrm{C}$ and $\mathrm{N}$ content with presumably different isotopic values (Jouquet et al. 2002, 2015). Our data show that isotopic ratios differ between nest samples and termite tissues (Fig. 1a). In the case of soil-feeding termites, isotopic ratios of both nests and the surrounding soil are highly similar (Tayasu et al. 1997), which is also evidenced by our data (Fig. 1a). However, there is an increase of approximately 5-9\%o and $2-3 \%$ for $\delta^{15} \mathrm{~N}$ and $\delta^{13} \mathrm{C}$, respectively, in tissues (Tayasu et al. 1997). Enrichment in ${ }^{13} \mathrm{C}$ or ${ }^{15} \mathrm{~N}$ is generally explained by isotopic fractionation during animal and microbial processing of organic compounds during the decomposition processes (Potapov et al. 2019). In termites, differences may further arise from the selective consumption of small soil particles richer in organic matter (characterized by higher $\delta^{15} \mathrm{~N}$ values) and/or their associated microorganisms, as well as from the activity of gut bacterial communities (Nadelhoffer and Fry 1994; Tayasu et al. 1997; Hyodo et al. 2008; Potapov et al. 2019).

Interestingly, the inquiline $C$. tuberosus exhibited higher $\delta^{13} \mathrm{C}$ and $\delta^{15} \mathrm{~N}$ values compared to all other species. This indicates that they feed on either a distinct diet, or consumed already processed, more humified organic matter and their associated microorganisms (Hyodo et al. 2008; Potapov et al. 2019). Furthermore, this species displayed the largest niche on both isotope ratios, confirming previous observations (Bourguignon et al. 2011). For a given species, variability in isotopic values might relate to the variety of decomposition states of the organic matter in the soil (Bourguignon et al. 2009, 2011). In addition, our results show that nests inhabited by $C$. tuberosus are significantly enriched in ${ }^{13} \mathrm{C}$ and marginally in ${ }^{15} \mathrm{~N}$ (Table S5), and that both isotopic ratios correlated with those of the corresponding tissue samples on their whole range. These results are consistent with a further degradation/humification of soil organic matter, indicating that nests, in various states of decomposition, may be the main food source of this insect (Peterson and Fry 1987; McCutchan et al. 2003; Hood-Nowotny and Knols 2007; Tiunov 2007; Hyodo et al. 2008; Potapov et al.
2019). Furthermore, some samples of $C$. tuberosus with the highest $\delta^{13} \mathrm{C}$ values (from nests G17-077, G17B-100 and G17B-138; Fig. 1b; labelled in Fig. S4) showed lower $\delta^{15} \mathrm{~N}$ values, which is compatible with nitrogen fixation by microorganisms (Peterson and Fry 1987; see below). Altogether, these results indicate that $C$. tuberosus feeds on reprocessed organic matter and is a generalist nest feeder.

\section{Gut microbiota composition of $C$. tuberosus and its hosts}

Gut bacteria deeply shaped the ecology and evolution of their hosts by being involved in several core processes such as food digestion and nutrient supplementation, the normal development of the intestine and the immune system, the protection against pathogens and the degradation of toxins, and even host behaviour and social interactions (Douglas 2015; Macke et al. 2017). Gut microbiota encompasses (1) the core microbiota, which are host-specific microbes assembled from diverse environments, which are under host genetic and immune control, as well as (2) a flexible pool of microbes, whose diversity and abundance are modulated by environmental diversity and external conditions (Moran and Sloan 2015; Tai et al. 2015; Shapira 2016).

Diet and gut microenvironment are the primary determinants of bacterial communities and changes in the relative abundance reflect adaptive mechanisms for dietary fluctuations (Abdul Rahman et al. 2015; Mikaelyan et al. 2015, 2017; Waidele et al. 2017). Accordingly, our results show that microbiota differ between species but are similar between colonies of the same species (Fig. 2). Interestingly, the gut microbiota of $C$. tuberosus (Termitinae) is also the most diverse compared to the ones of its hosts and it shares the highest number of OTUs with its main host, L. labralis (Syntermitinae), despite their phylogenetic remoteness (Fig. 2b, c). While contrary to endosymbionts, vertical transmission of gut microbiota is generally imperfect (Macke et al. 2017), it is different in termites where the exchange of stomodeal and proctodeal fluids among nestmates (trophallaxis) is the common rule (Nalepa et al. 2001). Also, recent phylogenetic studies on bacterial lineages evidenced rampant horizontal transfer over evolutionary time between termite hosts: gut microbiota is both transmitted vertically colony-to-offspring and horizontally through colony-to-colony transfer (Bourguignon et al. 2018). Horizontal transfer between species could occur through heterospecific cannibalism after agonistic encounters or through the consumption of nest material (Thorne and Haverty 1991; Nalepa et al. 2001). This suggests that the gut microbiota of $C$. tuberosus have been influenced by the gut communities of its hosts, and may be adapted to digest nest materials built by several species. 


\section{Nest-associated bacterial communities}

After gut passage, the soil organic matter is transformed into organo-mineral micro-aggregates incorporated as faeces in the building of the nest, and these nutrient-rich substrates facilitate the growth of microorganisms (Garnier-Sillam et al. 1985; Brauman 2000). Our results show that bacterial communities are drastically different between termite gut and nests, and that members of the phylum Actinobacteria dominate in the latter (Fig. 3; 1 vs $65 \%$ in relative abundance). Actinobacteria-dominated bacterial communities were also found in mounds of the soil-feeder Cubitermes niokoloensis; lineages from mounds differed from the surrounding soil and were more diverse (Fall et al. 2004, 2007). As a matter of fact, bacterial communities usually strongly differ between the termite gut, the nest and the surrounding soil (Ohkuma and Brune 2011; Manjula et al. 2016).

While the diet of wood-feeding termites consists of carbon-rich but nitrogen-poor food, soil feeders should not be limited by nitrogen (Waller and La Fage 1987; Brune and Ohkuma 2011). Nitrogen requirements of the latter are covered by the mineralization of peptides, amino sugars and microbial biomass present in the humus (Ji and Brune 2006; Brune and Dietrich 2015). This mineralization is evidenced by huge concentrations of ammonium in the faeces, which serve as a basis for nest building and protect this nitrogen form from leaching through adsorption onto the nest material (Ji and Brune 2006). However, in the case of secondary colonization of an arboreal nest, no further material is brought to the nest, and nitrogen supply may become limiting at some point. In termites, nitrogen economy can be achieved through controlled cannibalism of nestmates and the recycling of uric acid (Moore 1969). While this latter pathway is important in wood-feeding termites, its significance in soil feeders is not known (Potrikus and Breznak 1980, 1981; Brune and Ohkuma 2011; Thong-On et al. 2012). Preliminary data showed that transcripts of the gene encoding for urease, an enzyme involved in the catabolic pathway of uric acid (into ammonia), are detected in gut samples of several neotropical soil-feeding termites (M.M. and M.C., unpublished data), suggesting that this pathway for nitrogen economy may not be restricted to wood feeders.

Beside recycling pathways discussed above, one major feature of the symbiosis between termites and gut microorganisms is the fixation of atmospheric nitrogen (Tayasu et al. 1994). The gene nifH (encoding for the dinitrogenase reductase) is the key gene involved in this process (Ohkuma et al. 1999). Such a process may also occur in the nest material, and could be of importance in arboreal nests, to which no organic matter is brought when the colony of the nest-building species vanishes. Based on our analyses, potential nitrogen-fixing bacteria represent at least $2.33 \%$ of the community abundance in nest samples. However, our analysis is by no means exhaustive as it is based on published genomes and the quality of annotations. Nevertheless, our results suggest that a few bacteria in the nest might fix atmospheric nitrogen. Such a process would compensate for the consumption of nest material, a hypothesis which is further supported by the similarity of the $\mathrm{C}: \mathrm{N}$ ratio between $\mathrm{A}$ and $\mathrm{B}$ nests. However, the low concentration of the micronutrient molybdenum ( $30 \mu \mathrm{g} \mathrm{kg}^{-1}$ in our nest samples; see Table S6), an essential cofactor for some nitrogenases (Eady 1996), could be limiting as in other lowland tropical forests (Barron et al. 2009). Therefore, nitrogen fixation activity and its intensity remain to be firmly demonstrated through biological assays.

\section{Generalist inquiline and ecological success}

Cavitermes tuberosus colonizes nests of several arboreal termite species and can be considered as a broad-spectrum inquiline. In this study, we demonstrate that (1) this species feeds on the nest material and consumes already processed, more humified, nest organic matter; (2) its gut microbiota is much more diverse than that of its hosts, and probably adapted to digest nest materials from several species; and (3) a few bacteria in the nest might be able to fix atmospheric nitrogen, a process that would balance the consumption of the nest material. Furthermore, the endosymbiotic bacterium Wolbachia was recently shown to inhabit a bacteriome in the anterior part of the mesenteron of $C$. tuberosus to which it may supply essential nutrients (Hellemans et al. 2019b). Altogether, these features explain the ecological success of this inquiline, despite its inability to build its own nest.

Acknowledgments We are grateful to the late Philippe Cerdan, to Régis Vigouroux and the staff of the Laboratoire Environnement HYDRECO of Petit Saut (EDF-CNEH) for logistic support during field work. We thank Xavier Goux and Nicolas Kaczmarek for their help in the field, and Alexandre Van Baekel for assistance during ICPOES measurements.

Author contribution statement SH and YR designed the study. SH, MM, DF, and YR collected the material. SH and TD performed soil analyses; SH and GL performed isotopic analyses; and MM and MC performed Illumina sequencing and subsequent analyses. All authors contributed significantly to the manuscript and approved the final version.

Funding This work was supported by the Belgian National Fund for Scientific Research F.R.S.-FNRS (PhD fellowship to SH and Grant PDR T.0065.15 to YR) and by the Luxembourg National Research Fund through an FNR 2014 CORE project (OPTILYS; Exploring the higher termite lignocellulolytic system to optimize the conversion of biomass into energy and useful platform molecules/C14/SR/8286517). GL and DF are appointed as Research Associates for the F.R.S.-FNRS.

\section{Compliance with ethical standards}

Conflict of interest We declare we have no competing interests. 
Data archiving Sequences produced for this study have been deposited in GenBank repository under Project accession KBWO01000000 (see details in Supplementary Table S2).

\section{References}

Abdul Rahman N, Parks DH, Willner DL et al (2015) A molecular survey of Australian and North American termite genera indicates that vertical inheritance is the primary force shaping termite gut microbiomes. Microbiome 3:1-16. https://doi.org/10.1186/s4016 8-015-0067-8

Abe T (1987) Evolution of life types in termites. In: Kawano S, Connell JH, Hidaka T (eds) Evolution and coadaptation in biotic communities. Univeristy of Tokyo Press, Tokyo, pp 125-148

Apolinário FE, Martius C (2004) Ecological role of termites (Insecta, Isoptera) in tree trunks in central Amazonian rain forests. For Ecol Manage 194:23-28. https://doi.org/10.1016/j.foreco.2004.01.052

Araujo RL (1977) Further notes in the bionomics of Serritermes (Isoptera). Rev Bras Entomol 21:31-32

Barron AR, Wurzburger N, Bellenger JP et al (2009) Molybdenum limitation of asymbiotic nitrogen fixation in tropical forest soils. Nat Geosci 2:42-45. https://doi.org/10.1038/ngeo366

Beck MW (2017) ggord: ordination plots with ggplot 2. R package version 1.0.0. https://zenodo.org/badge/latestdoi/35334615

Benjamini Y, Hochberg Y (1995) Controlling the false discovery rate: a practical and powerful approach to multiple testing. J R Stat Soc Ser B 57:289-300

Bignell DE, Eggleton P (2000) Termites in ecosystems. In: Abe T, Bignell DE, Higashi M (eds) Termites: evolution, sociality, symbioses, ecology. Kluwer Academic Publishers, Dordrecht, pp 363-387

Bottinelli N, Jouquet P, Capowiez Y et al (2015) Why is the influence of soil macrofauna on soil structure only considered by soil ecologists? Soil Tillage Res 146:118-124. https://doi.org/10.1016/j.still .2014 .01 .007

Bourguignon T, Šobotník J, Lepoint G et al (2009) Niche differentiation among neotropical soldierless soil-feeding termites revealed by stable isotope ratios. Soil Biol Biochem 41:2038-2043. https ://doi.org/10.1016/j.soilbio.2009.07.005

Bourguignon T, Šobotník J, Lepoint G et al (2011) Feeding ecology and phylogenetic structure of a complex neotropical termite assemblage, revealed by nitrogen stable isotope ratios. Ecol Entomol 36:261-269. https://doi.org/10.1111/j.1365-2311.2011.01265.x

Bourguignon T, Drouet T, Šobotník J et al (2015a) Influence of soil properties on soldierless termite distribution. PLoS One 10:e0135341. https://doi.org/10.1371/journal.pone.0135341

Bourguignon T, Lo N, Cameron SL et al (2015b) The evolutionary history of termites as inferred from 66 mitochondrial genomes. Mol Biol Evol 32:406-421. https://doi.org/10.1093/molbev/msu308

Bourguignon T, Lo N, Šobotník J et al (2017) Mitochondrial phylogenomics resolves the global spread of higher termites, ecosystem engineers of the tropics. Mol Biol Evol 34:589-597. https://doi. org $/ 10.1093 / \mathrm{molbev} / \mathrm{msw} 253$

Bourguignon T, Lo N, Dietrich C et al (2018) Rampant host switching shaped the termite gut microbiome. Curr Biol 28:649-654.e2. https://doi.org/10.1016/j.cub.2018.01.035

Brauman A (2000) Effect of gut transit and mound deposit on soil organic matter transformations in the soil feeding termite: a review. Eur J Soil Biol 36:117-125

Brune A, Dietrich C (2015) The gut microbiota of termites: digesting the diversity in the light of ecology and evolution. Annu Rev Microbiol 69:145-166. https://doi.org/10.1146/annurev-micro $-092412-155715$
Brune A, Ohkuma M (2011) Role of the termite gut microbiota in symbiotic digestion. In: Bignell DE, Roisin Y, Lo N (eds) Biology of termites: a modern synthesis. Springer, Dordrecht, pp 439-475

Constantino R (1991) Termites (Isoptera) from the lower Japurá river, Amazonas state, Brazil. Bol Mus Para Emílio Goeldi, séries Zool 7:189-224

Cosson JF, Ringuet S, Claessens O et al (1999) Ecological changes in recent land-bridge islands in French Guiana, with emphasis on vertebrate communities. Biol Conserv 91:213-222. https://doi. org/10.1016/S0006-3207(99)00091-9

Davies RG (2002) Feeding group responses of a Neotropical termite assemblage to rain forest fragmentation. Oecologia 133:233-242. https://doi.org/10.1007/s00442-002-1011-8

Davies RG, Hernández LM, Eggleton P et al (2003) Environmental and spatial influences upon species composition of a termite assemblage across neotropical forest islands. J Trop Ecol 19:509-524. https://doi.org/10.1017/S0266467403003560

de Granville J-J (1988) Phytogeographical characteristics of the Guianan forests. Taxon 37:578-594

Donovan SE, Eggleton P, Bignell DE (2001) Gut content analysis and a new feeding group classification of termites. Ecol Entomol 26:356-366. https://doi.org/10.1046/j.1365-2311.2001.00342.x

Douglas AE (2015) Multiorganismal insects: diversity and function of resident microorganisms. Annu Rev Entomol 60:17-34. https:// doi.org/10.1146/annurev-ento-010814-020822

Eady RR (1996) Structure-function relationships of alternative nitrogenases. Chem Rev 96:3013-3030. https://doi.org/10.1021/cr950 $057 \mathrm{~h}$

Edgar RC (2010) Search and clustering orders of magnitude faster than BLAST. Bioinformatics 26:2460-2461. https://doi.org/10.1093/ bioinformatics/btq461

Eggleton P, Tayasu I (2001) Feeding groups, lifetypes and the global ecology of termites. Ecol Res 16:941-960. https://doi.org/10.104 6/j.1440-1703.2001.00444.x

Emerson AE (1925) The termites of Kartabo, Bartica District, British Guiana. Zoologica 6:291-459

Emerson AE (1956) Regenerative behavior and social homeostasis of termites. Ecology 37:248-258

Fall S, Nazaret S, Chotte JL, Brauman A (2004) Bacterial density and community structure associated with aggregate size fractions of soil-feeding termite mounds. Microb Ecol 48:191-199. https:// doi.org/10.1007/s00248-003-1047-2

Fall S, Hamelin J, Ndiaye F et al (2007) Differences between bacterial communities in the gut of a soil-feeding termite (Cubitermes niokoloensis) and its mounds. Appl Environ Microbiol 73:51995208. https://doi.org/10.1128/AEM.02616-06

Florencio DF, Rosa CS, Marins A et al (2011) How to preserve termite samples in the field for carbon and nitrogen stable isotope studies? Rapid Commun Mass Spectrom 25:243-246. https://doi. org/10.1002/rcm.4820

Florencio DF, Marins A, Rosa CS et al (2013) Diet segregation between cohabiting builder and inquiline termite species. PLoS One 8:e66535. https://doi.org/10.1371/journal.pone.0066535

Fournier D, Hellemans S, Hanus R, Roisin Y (2016) Facultative asexual reproduction and genetic diversity of populations in the humivorous termite Cavitermes tuberosus. Proc R Soc B 283:20160196. https://doi.org/10.1098/rspb.2016.0196

Garnier-Sillam E, Harry M (1995) Distribution of humic compounds in mounds of some soil-feeding termite species of tropical rainforests: its influence on soil structure stability. Insect Soc 42:167185. https://doi.org/10.1007/BF01242453

Garnier-Sillam E, Villemin G, Toutain F, Renoux J (1985) Formation of organo-mineral micro-aggregates in termites faeces. $\mathrm{C} \mathrm{r}$ séances Acad sci Sér 3 Sci vie 301:213-218

Hellemans S, Bourguignon T, Kyjaková P et al (2017a) Mitochondrial and chemical profiles reveal a new genus and species of 
Neotropical termite with snapping soldiers, Palmitermes impostor (Termitidae: Termitinae). Invertebr Syst 31:394-405. https://doi. org/10.1071/IS16089

Hellemans S, Fournier D, Hanus R, Roisin Y (2017b) Secondary queens in the parthenogenetic termite Cavitermes tuberosus develop through a transitional helper stage. Evol Dev 19:253-262. https://doi.org/10.1111/ede.12240

Hellemans S, Fournier D, Hanus R, Roisin Y (2019a) Sex ratio variations among years and breeding systems in a facultatively parthenogenetic termite. Insect Soc 66:129-138. https://doi.org/10.1007/ s00040-018-0667-y

Hellemans S, Kaczmarek N, Marynowska M et al (2019b) Bacteriome-associated Wolbachia of the parthenogenetic termite Cavitermes tuberosus. FEMS Microbiol Ecol 95:fiy235. https://doi. org/10.1093/femsec/fiy 235

Hood-Nowotny R, Knols BGJ (2007) Stable isotope methods in biological and ecological studies of arthropods. Entomol Exp Appl 124:3-16. https://doi.org/10.1111/j.1570-7458.2007.00572.x

Hyodo F, Tayasu I, Konaté S et al (2008) Gradual enrichment of ${ }^{15} \mathrm{~N}$ with humification of diets in a below-ground food web: relationship between ${ }^{15} \mathrm{~N}$ and diet age determined using ${ }^{14} \mathrm{C}$. Funct Ecol 22:516-522. https://doi.org/10.1111/j.1365-2435.2008.01386.x

Jackson AL, Inger R, Parnell AC, Bearhop S (2011) Comparing isotopic niche widths among and within communities: SIBER-stable isotope bayesian ellipses in R. J Anim Ecol 80:595-602. https ://doi.org/10.1111/j.1365-2656.2011.01806.x

Ji R, Brune A (2006) Nitrogen mineralization, ammonia accumulation, and emission of gaseous $\mathrm{NH}_{3}$ by soil-feeding termites. Biogeochemistry 78:267-283. https://doi.org/10.1007/s1053 3-005-4279-z

Ji R, Kappler A, Brune A (2000) Transformation and mineralization of synthetic ${ }^{14} \mathrm{C}$-labeled humic model compounds by soil-feeding termites. Soil Biol Biochem 32:1281-1291

Jouquet P, Lepage M, Velde B (2002) Termite soil preferences and particle selections: strategies related to ecological requirements. Insect Soc 49:1-7. https://doi.org/10.1007/s00040-002-8269-z

Jouquet P, Guilleux N, Chintakunta S et al (2015) The influence of termites on soil sheeting properties varies depending on the materials on which they feed. Eur J Soil Biol 69:74-78. https://doi. org/10.1016/j.ejsobi.2015.05.007

Jouquet P, Bottinelli N, Shanbhag RR et al (2016) Termites: the neglected soil engineers of tropical soils. Soil Sci 181:157-165. https://doi.org/10.1097/SS.0000000000000119

Krishna K, Grimaldi DA, Krishna V, Engel MS (2013a) Treatise on the Isoptera of the world. 1. Introduction. Bull Am Mus Nat Hist 377:1-200. https://doi.org/10.1206/377.1

Krishna K, Grimaldi DA, Krishna V, Engel MS (2013b) Treatise on the Isoptera of the world. 6. Termitidae (Part Three), Incertae sedis, taxa excluded from Isoptera. Bull Am Mus Nat Hist 377:1989_ 2432. https://doi.org/10.1206/377.6

Macke E, Tasiemski A, Massol F et al (2017) Life history and ecoevolutionary dynamics in light of the gut microbiota. Oikos 126:508-531. https://doi.org/10.1111/oik.03900

Manjula A, Pushpanathan M, Sathyavathi S et al (2016) Comparative analysis of microbial diversity in termite gut and termite nest using ion sequencing. Curr Microbiol 72:267-275. https://doi. org/10.1007/s00284-015-0947-y

Martius C (1997) The termites. In: Junk W (ed) Ecological studies 126. The Central-Amazonian floodplain: ecology of a pulsing system. Springer, Berlin, pp 361-371

Marynowska M, Goux X, Sillam-Dussès D et al (2017) Optimization of a metatranscriptomic approach to study the lignocellulolytic potential of the higher termite gut microbiome. BMC Genomics 18:681. https://doi.org/10.1186/s12864-017-4076-9

Mathews AGA (1977) Studies on termites from the Mato Grosso state, Brazil. Academia Brasileira de Ciências, Rio de Janeiro
McCutchan JH, Lewis WM, Kendall C, McGrath CC (2003) Variation in trophic shift for stable isotope ratios of carbon, nitrogen, and sulfur. Oikos 102:378-390. https://doi.org/10.103 4/j.1600-0706.2003.12098.x

Mikaelyan A, Dietrich C, Köhler T et al (2015) Diet is the primary determinant of bacterial community structure in the guts of higher termites. Mol Ecol 24:5284-5295. https://doi. org/10.1111/mec.13376

Mikaelyan A, Meuser K, Brune A (2017) Microenvironmental heterogeneity of gut compartments drives bacterial community structure in wood- and humus-feeding higher termites. FEMS Microbiol Ecol 93:fiw210. https://doi.org/10.1093/femsec/fiw21 0

Moore BP (1969) Biochemical studies in termites. In: Krishna K, Weesner FM (eds) Biology of termites, vol 1. Academic Press, New-York, pp 407-432

Moran NA, Sloan DB (2015) The hologenome concept: helpful or hollow? PLoS Biol 13:e1002311. https://doi.org/10.1371/journ al.pbio. 1002311

Myles TG (1999) Review of secondary reproduction in termites (Insecta: Isoptera) with comments on its role in termite ecology and social evolution. Sociobiology 33:1-91

Nadelhoffer KJ, Fry B (1994) Nitrogen isotope studies in terrestrial ecosystems. In: Lajtha K, Michener RH (eds) Stable isotopes in ecology and environmental science. Blackwell Science Ltd, Oxford, pp 22-44

Nalepa CA, Bignell DE, Bandi C (2001) Detritivory, coprophagy, and the evolution of digestive mutualisms in Dictyoptera. Insect Soc 48:194-201. https://doi.org/10.1007/PL00001767

Noirot C (1970) The nest of termites. In: Krishna K, Weesner FM (eds) Biology of termites, vol 2. Academic Press, New York, pp 73-125

Ohkuma M, Brune A (2011) Diversity, structure, and evolution of the termite gut microbial community. In: Bignell DE, Roisin Y, Lo N (eds) Biology of termites: a modern synthesis. Springer, Dordrecht, pp 413-438

Ohkuma M, Noda S, Kudo T (1999) Phylogenetic diversity of nitrogen fixation genes in the symbiotic microbial community in the gut of diverse termites. Appl Environ Microbiol 65:4926-4934

Pansu M, Gautheyrou J (2006) Handbook of soil analysis: mineralogical, organic and inorganic methods. Springer, Berlin

Parnell AC, Inger R, Bearhop S, Jackson AL (2010) Source partitioning using stable isotopes: coping with too much variation. PLoS One 5:e9672. https://doi.org/10.1371/journal.pone.0009672

Peterson BJ, Fry B (1987) Stable isotopes in ecosystem studies. Annu Rev Ecol Evol Syst 18:293-320

Potapov AM, Tiunov AV, Scheu S (2019) Uncovering trophic positions and food resources of soil animals using bulk natural stable isotope composition. Biol Rev 94:37-59. https://doi.org/10.1111/ brv. 12434

Potrikus CJ, Breznak JA (1980) Uric acid in wood-eating termites. Insect Biochem 10:19-27. https://doi.org/10.1016/00201790(80)90034-7

Potrikus CJ, Breznak JA (1981) Gut bacteria recycle uric acid nitrogen in termites: a strategy for nutrient conservation. Proc Natl Acad Sci USA 78:4601-4605. https://doi.org/10.1073/pnas.78.7.4601

Pruesse E, Quast C, Knittel K et al (2007) SILVA: a comprehensive online resource for quality checked and aligned ribosomal RNA sequence data compatible with ARB. Nucleic Acids Res 35:71887196. https://doi.org/10.1093/nar/gkm864

R Development Core Team (2015) R: A language and environment for statistical computing. R Foundation for Statistical Computing, Vienna

Rückamp D, Amelung W, Borma LS et al (2009) Carbon and nutrient leaching from termite mounds inhabited by primary and secondary termites. Appl Soil Ecol 43:159-162. https://doi. org/10.1016/j.apsoil.2009.06.012 
Rückamp D, Martius C, Bornemann L et al (2012) Soil genesis and heterogeneity of phosphorus forms and carbon below mounds inhabited by primary and secondary termites. Geoderma 170:239-250. https://doi.org/10.1016/j.geoderma.2011.10.004

Schloss PD, Westcott SL, Ryabin T et al (2009) Introducing mothur: open-source, platform-independent, community-supported software for describing and comparing microbial communities. Appl Environ Microbiol 75:7537-7541. https://doi.org/10.1128/ AEM.01541-09

Schnitzer M (1971) Characterization of humic constituents by spectroscopy. In: McLaren AD, Skujins J (eds) Soil biochemistry, vol 2. Marcel Dekker, New York, pp 60-95

Shapira M (2016) Gut microbiotas and host evolution: scaling up symbiosis. Trends Ecol Evol 31:539-549. https://doi.org/10.1016/j. tree.2016.03.006

Shellman-Reeve JS (1997) The spectrum of eusociality in termites. In: Choe JC, Crespi BJ (eds) The evolution of social behavior in insects and arachnids. Cambridge University Press, Cambridge, pp 52-93

Su L, Yang L, Huang S et al (2017) Variation in the gut microbiota of termites (Tsaitermes ampliceps) against different diets. Appl Biochem Biotechnol 181:32-47. https://doi.org/10.1007/s1201 0-016-2197-2

Tai V, James ER, Nalep CA et al (2015) The role of host phylogeny varies in shaping microbial diversity in the hindguts of lower termites. Appl Environ Microbiol 81:1059-1070. https://doi. org/10.1128/AEM.02945-14
Tayasu I, Sugimoto A, Wada E, Abe T (1994) Xylophagous termites depending on atmospheric nitrogen. Naturwissenschaften 81:229 231. https://doi.org/10.1007/BF01138550

Tayasu I, Abe T, Eggleton P, Bignell DE (1997) Nitrogen and carbon isotope ratios in termites: an indicator of trophic habit along the gradient from wood-feeding to soil-feeding. Ecol Entomol 22:343-351. https://doi.org/10.1046/j.1365-2311.1997.00070.x

Thong-On A, Suzuki K, Noda S et al (2012) Isolation and characterization of anaerobic bacteria for symbiotic recycling of uric acid nitrogen in the gut of various termites. Microbes Environ 27:186-192. https://doi.org/10.1264/jsme2.ME11325

Thorne BL, Haverty MI (1991) A review of intracolony, intraspecific, and interspecific agonism in termites. Sociobiology 19:115-145

Tiunov AV (2007) Stable isotopes of carbon and nitrogen in soil ecological studies. Biol Bull 34:395-407. https://doi.org/10.1134/ S1062359007040127

Waidele L, Korb J, Voolstra CR et al (2017) Differential ecological specificity of protist and bacterial microbiomes across a set of termite species. Front Microbiol 8:1-13. https://doi.org/10.3389/ fmicb.2017.02518

Waller DA, La Fage JP (1987) Nutritional ecology of termites. In: Slansky F, Rodriguez J (eds) Nutritional ecology of insects, mites, and spiders. Wiley, New York, pp 487-532

Wood TG (1988) Termites and the soil environment. Biol Fertil Soils 6:228-236. https://doi.org/10.1007/BF00260819 